\title{
Contraceptive use among sexually active female adolescents in Ethiopia: Trends and determinants from national demographic and health surveys
}

\author{
Alemi Kebede Olika ( $\square$ alemikebede@gmail.com ) \\ Jimma University \\ Sena Belina Kitila \\ Jimma University \\ Yonas Biratu Terfa \\ Jimma University \\ Ayantu Kebede Olika \\ Jimma University
}

\section{Research}

Keywords: Ethiopia, adolescent, contraceptives, Demographic and health survey, Determinants

Posted Date: February 8th, 2021

DOI: https://doi.org/10.21203/rs.3.rs-34459/v5

License: (a) (i) This work is licensed under a Creative Commons Attribution 4.0 International License. Read Full License 


\section{Abstract}

Background: Sexual and reproductive health and right of adolescents is a global priority as the reproductive choices made by them have a massive impact on their health, wellbeing, education, and economy. Teenage pregnancy is a public health issue and a demographic challenge in Ethiopia. A contraceptive method is best for sexually active adolescents to prevent pregnancies and its related complications. However, little is known about the trends in contraceptive use and its determinants among adolescent girls in Ethiopia. Therefore, this study was designed to examine the trends and factors associated with contraceptive use among sexually active girls aged 15-19 years in Ethiopia by using Ethiopian demographic and health survey data.

Methods: Four Ethiopian demographic and health survey data were used to examine trends of contraceptive methods use. To identify factors associated with contraceptive use, the 2016 Ethiopian demographic and health survey data were used. The data was downloaded from the demographic and health survey program database and extracted for sexually active adolescent girls. Data were weighted for analysis and analyzed using SPSS version 21. Descriptive analysis was used to describe the independent variables of the study. A multivariable logistic regression model was used to identify factors associated with contraceptive use and adjusted odds ratios with $95 \%$ confidence interval were presented for significant variables. Variables with a $p$-value less than 0.05 were considered as significantly associated with contraceptive use.

Results: Contraceptive method use had increased significantly from $6.9 \%$ in 2000 to $39.6 \%$ in 2016 among sexually active adolescent girls in Ethiopia. The odds of contraceptive use were lower among female adolescents who had no formal education (AOR $=0.044 ; 95 \% \mathrm{Cl}=0.008-0.231)$ and attended primary education $(\mathrm{AOR}=0.101 ; 95 \% \mathrm{Cl}=0.024-0.414)$. But the odds were higher among adolescents from a wealthy background ( $\mathrm{AOR}=3.662 ; 95 \% \mathrm{Cl}=1.353-9.913)$ and those who have visited health facilities and were informed about family planning (AOR=3.115; 95\% $\mathrm{Cl}=1.385-7.007)$.

Conclusion: There is an increment in the trend of contraceptive use among sexually active female adolescents in Ethiopia between 2000 to 2016. Significant variations in the use of modern contraception by wealth status, educational level and visited a health facility, and being informed about family planning were observed. Improving the economic and educational status of young women, and provision of information may help in improving contraceptive use in Ethiopia.

\section{Plain English Summary}

Adolescent contributes up to 16 per cent of the world's population. Sexual and reproductive health and right of these populations is a global priority. Teenage pregnancy is a public health issue and a demographic challenge in Ethiopia. A contraceptive method is best for sexually active adolescents to prevent pregnancies and its related complications. 
Data for this study are from the four Ethiopian Demographic and Health Surveys [EDHS] conducted in $2000,2005,2011$, and 2016. Data for sexually active adolescent girls were extracted from the data set.

The trend of contraceptive use among adolescents is increasing from time to time. However, more than three-fifth of the sexually active female adolescents are still not using any type of contraception. There were significant variations in the use of modern contraception by background characteristics of the respondents. In all four rounds of the EDHS, modern contraceptive use was common among adolescents in 18-19 years, who attended secondary and above educational level, lived in urban areas, and was from wealthy family groups.

\section{Introduction}

Adolescence is a critical phase in life and a time of social and biological transition between childhood and adulthood that entails numerous milestones and opportunities, roles, and responsibilities $(1-3)$. Adolescents are individuals in the age range of 10-19 years. This age group constitutes 16 per cent of the world's population and is one of the fastest-growing cohorts, and their contribution is vital in achieving several developmental goals (4-6). Global developmental goals and strategies have recognized the importance of adolescent's health and rights (7-9). Sexual and reproductive health and rights (SRHR) of these populations is a global priority as the reproductive choices made by them have a massive impact on their health, wellbeing, education, and economy $(10,11)$.

In low- and middle-income countries (LMICs), unintended pregnancy accounted for half of all pregnancies among girls and more than half of these pregnancies result in abortion (10). Annually, about 16 unsafe abortions per 1,000 occur in LMICs among girls under the age of 20 years (12). Pregnancy and childbirth complications are the leading cause of death among adolescent girls globally, with a higher proportion in LMICs $(13,14)$. Besides, children born to adolescent girls are more likely to have low birth weight $(15)$. Access to sexual and reproductive health information and services are essential in averting these problems and deaths $(1,3,11,16)$.

A contraceptive method is best for sexually active adolescents to prevent pregnancies and its related complications (10). For instance, the use of modern contraceptives prevented an estimated 308 million unplanned pregnancies in 2017 (11). If the modern contraceptive method were accessible for adolescents with unmet needs, unintended pregnancies would drop by $59 \%$ (10). Also, expanding the contraceptive method mix can serve as an effective strategy to prevent unsafe abortion (17). Hence, all adolescents who want to prevent pregnancy should be able to obtain and use contraception (18).Available evidence shows that sexually active unmarried adolescents do not seek to become pregnant and the married wish not to become pregnant at a young age or wish to delay a second pregnancy $(11,14,19,20)$. However, only, $40 \%$ of adolescents are using an effective contraceptive method in LMICs $(10,21)$. Despite having clear needs, adolescents often fail to access contraceptives, and unplanned pregnancies happen despite the best of contraceptive intentions. There are disparities in contraceptive use between different age groups 
and young people have inadequate access to sexual and reproductive health information and services $(2,3,22)$.

In Ethiopia, teenage pregnancy is a public health issue and a demographic challenge. The proportion varies geographically with 15\% in rural and 5\% in urban in 2016 (22). Preventing teenage pregnancies and fertility is among the priority issues of the Ethiopian Federal Ministry of Health (23). Ethiopia's government is implementing youth policies and national adolescent and youth health strategies to support young people in increasing their access to sexual and reproductive health services (24-26).

Though there are primary studies on contraceptive use in Ethiopia (27-28), there is a lack of evidence concerning trends in contraceptive use and its determinants among girls aged 15 to 19 years from the data that represent the national level picture. To effectively respond to this growing population's reproductive health needs, it is imperative to understand their contraception practices. Therefore, this study aimed to examine the trends and correlations of contraceptive use among sexually active adolescents in Ethiopia by using the Ethiopian demographic and health survey data. The study's findings will be useful for health planners, policymakers, and developmental partners who are working to improve the health and well-being of adolescents in Ethiopia. Furthermore, it will assist in designing programs and strategies to increase coverage, quality, and equity of adolescent girl's reproductive health at the country level.

\section{Data And Method}

\section{Data source}

Data for this study were extracted from the four rounds $(2000,2005,2011$, and 2016) of EDHS. EDHS consists of a sample of households obtained through a two-stage stratified sampling procedure. Regions were stratified into urban and rural areas. Each stratum was clustered into Enumeration areas (EAs) based on the 2007 Ethiopian housing and population census. Samples of EAs were selected independently in each stratum in two stages. The first stage involves randomly selecting clusters, EAs. A sample of households is drawn from a listing of households in each of the sampled clusters at the second stage.

The information about contraceptive use was collected from all non-pregnant, fecund reproductive age women using a pretested questionnaire. In this study, all four rounds of EDHS data were used to describe the trends of contraceptive use among sexually active female adolescents. The 2016 EDHS data were employed to analyze the determinants of contraceptive use. Permission to use the data was granted by the Measure DHS program on April 1, 2019.

\section{Opperational definitions}

Sexually active: Those respondents who reported that they have had sexual intercourse, irrespective of their marital status in the last four weeks at the time of interview. 
Contraceptive use: Respondents who at the time of interview said they or their partner are using any contraceptive method to delay or avoid becoming pregnant. It was dichotomous denoting users and nonusers of contraceptive methods.

Current use of modern contraception: Current users of modern contraceptives include young women who said that they or their partner are currently using any of the following modern methods of contraception, such as female sterilization, male sterilization, the pill, injectable, intrauterine device, implant, condom, and emergency contraception at the time of the survey.

Study_population and sample size

The study populations for the study were sexually active adolescent girls between 15-19 years. During the four rounds of the survey, 3,710, 3,266, 4,009, and 3,381 adolescent girls have participated respectively. Of the total adolescent girls who participated in the study, 762, 287, 632, and 504 were sexually active in the last four weeks before data collection and used for analysis in 2000, 2005, 2011, and 2016 respectively.

\section{Study variables}

The dependent variable for this study was contraceptive use. Independent variables include age, educational status, religion, ethnicity, marital status, working currently, wealth status, visited a health facility in the last 12 months before the survey, being informed about family planning (FP) at the health facility, heard information about FP from radio, watch on Television (TV) and read it on newspaper and place of residence.

For this study, some of the study variables were re-coded to suit the purpose of the study while some were used as they are in the original data set. For instance, religious affiliation was re-coded into orthodox Christian, other Christian, Muslim and other, by combining catholic and protestant for other Christian. Wealth status was also re-coded into poor, average, and rich by combining "poorer" and "poor" for poor and "rich" and "richer" for rich. The highest education level was re-coded into no formal education, primary, and second and above by combining secondary and higher.

\section{Data analysis}

The data was downloaded from the demographic and health survey program database. The data for sexually active adolescent girls were extracted and data cleaning was done before any analysis. The analysis was performed by using IBM SPSS Statistics for Windows, Version 21.0. Armonk, NY: IBM Corp; 2012. Before any statistical analysis, standard EDHS sample weights were applied to account for the unequal probability of selection in the sample and non-response. The recommended procedure on how to weight DHS data in SPSS was followed. The weighting variable used was women's individual sample weight, since the study unit of analysis is women. The weight variable was created by dividing the individual women sample weight variable by $1,000,000$. 
Descriptive analysis was used to describe the background characteristics of the study participants. Multicollinearity was checked before running logistic regression using variance inflation factor. The maximum value of the variance inflation factor was 1.119, indicating that the absence of multicollinearity. Binary and multiple logistic regressions were employed to identify candidate variables and examine the determinants of contraceptive use respectively. Adjusted odds ratios with $95 \%$ confidence interval were presented for significant variables in the final model to estimate the likelihood of contraceptive use among various categories of adolescents. Variables with a $p$-value less than 0.05 were considered as significantly associated with contraceptive use. All figures and tables in the report depict weighted numbers and percentages.

\section{Results}

\section{Trends in contraceptive use}

The trends of contraceptive use among sexually active female adolescents increased from 6.9 per cent in 2000 to 39.6 per cent in 2016. The proportion of modern contraceptive use increased by 8.7 per cent between 2000 and 2005 and nearly doubled between 2005 to 2011. Modern contraception use continuously increased between the years 2005 and 2016 and, more than 10 per cent increment was observed between 2011 and 2016 (Figure 1).

\section{Disparities in contraceptive use by background characteristics of respondents}

The proportion of contraceptive use varies significantly with age, place of residence, educational level, and household wealth status of study subjects. In all four rounds of the EDHS, modern contraceptive use was common among adolescents in 18-19 years, who attended secondary and above educational level, lived in urban areas, and was from wealthy family groups. Between 2005 and 2011, the proportion of girls with secondary and above education and using modern contraception methods did not change whereas it declined by 6.3 per cent between 2011 and 2016 (Figure 2).

\section{Modern contraceptive utilization trends by method mix}

The trends in the mix of currently used modern methods indicated promising improvement. The share of the long-acting reversible contraceptive methods such as Norplant/implants among sexually active adolescent girls meaningfully increased by more than 6 percentage between 2000 to 2016. Intrauterine device (IUD) use did not increase as compared to implants. Utilization of Implants increased by 6.3 per cent, whereas only 1.1 per cent increment was recorded for IUD in 2016. Among short-term methods, the share of injection contraceptive method had been considerably increased by more than 25 per cent from the year 2000 to 2016. The use of condoms had significantly declined between the years 2005 and 2016 from $1.7 \%$ to $0.1 \%$ (Figure 3 ).

Contraceptive use and its determinants from 2016 EDHS data

Characteristics of sexually active adolescent girls from EDHS 2016 
A total of 504 sexually active adolescent girls were considered for this study. The mean age of the respondents was 17.73 years $(S D \pm 1.124)$. The mean ages at first cohabitation and first sexual intercourses were 15.59 years $(S D \pm 1.734)$ and 15.63 years $(S D \pm 1.751)$ years respectively. Nearly half $(225,47.3 \%)$ of adolescent girls cohabited at age 15 years or less.

Three-fifth (60.6\%) of the sexually active adolescent girls had attained primary education and 440 $(87.3 \%)$ were rural residents. While the majority $(458,91.0 \%)$ of study subjects were married, and 125 (24.8\%) of them were from the low socioeconomic group. Slightly more than two two-fifth $(41.9 \%)$ and 199 (39.5\%) of the girls were Muslims and Oromo by their religion and ethnicity respectively. More than three-fourth $(79.7 \%)$ of respondents were not working at the time of the survey (Table 1 ).

\section{Awareness and knowledge about fertility and contraceptive methods}

Among sexually active adolescent girls, almost all (98\%) of them had knowledge about contraceptive methods. Only 18.1, 13.4, and 4.2 per cent of girls reported that they had heard about FP messages on radio, watched on television, and read it in newspaper/magazine respectively in the last few months before the survey. More than three-fourth $(79.9 \%)$ of girls reported that field workers did not visit them in the last 12 months before the survey. Out of those visited by fieldworkers, only $9.9 \%$ of fieldworkers talked about FP. Additionally, 77 (15.3\%) of girls were informed about FP during their health facility visit in the last 12months (Table 2).

\section{Factors associated with contraceptive use among sexually active adolescents}

In binary logistic regression, eleven variables had a significant relationship with adolescent girls' contraceptive use. These include respondent's and partner's educational and occupational status, current working status, wealth status, visited by a field worker in the last 12 months, informed about FP at a health facility, place of residence, heard about FP messages on radio, and watched on television in the last few months were considered for multivariate analysis.

The odds of contraceptive use were nearly $96 \%$ (AOR=0.044; $95 \% \mathrm{Cl}=0.008-0.231)$ and $90 \%(\mathrm{AOR}=0.101$; $95 \% \mathrm{Cl}=0.024-0.414)$ less likely among sexually active female adolescent who had no formal education and primary education respectively as compared to those who had attained secondary and higher education. Adolescents in a rich wealthy background status were three-times more likely to use contraceptive methods than their counterparts (AOR=3.662; 95\% $\mathrm{Cl}=1.353-9.913$ ). The odds were threetimes among respondents who had visited health facilities and informed about FP as compared to those uninformed about FP during their visit (AOR=3.115; 95\% $\mathrm{Cl}=1.385-7.007)$ (Table 3).

\section{Discussion}

This study showed that more than nine out of ten adolescents were married, and about half were cohabiting at age 15 years and less than; more than three years earlier compared to the recommended age at marriage in Ethiopia. This showed the practice of very early marriage and early sexual activities 
among adolescent girls. Early marriage often results from the traditional and cultural family values that justify control over women's sexuality and fertility (29-31). Such practices have a direct impact on girls' education and future carrier (32). It has also a negative consequence on the economic development of nations in addition to causing a significant health risk both to a girl, and her baby (33). This was due to an extended time that the girls spend in childbearing years that cause an increase in fertility and population growth. The evidence also indicated that in the marriage union, the frequency of sexual activity is higher than in those who are not, hence in the absence of contraception there is a greater likelihood of occurrence of pregnancy (29).

During the last two decades, a growing trend was observed in the use of contraceptives by adolescent girls in Ethiopia. Contraceptive use among sexually active girls increased by six-folds between 2005 to 2016 EDHS. This may be contributed to the implementation of several interventions such as youthfriendly health services and innovative health extension program that brings health services including FP to the communities' home $(34,35)$. There is also a national political commitment to FP in Ethiopia, governments and nongovernmental organizations have increased resource allocations for contraceptive security and delivery (29). Further, the provision of short-term contraception methods by the private sectors may have also played an important role in increasing young women's access to contraceptive services in Ethiopia (30).

The proportion of sexually active female adolescent contraceptive users relying on the IUD and implants increased substantially from no reported users in 2000 to $1.1 \%$ and $6.3 \%$ in 2016 respectively. However, IUD use did not increase compared to implants. This may be because starting from 2009 insertion of the implant was cascaded to the health post level, and training was given to the health extension workers on the provision of the service (36). Despite the progress that has been achieved, a considerable number of sexually active adolescent girls use short-acting methods, especially injectable, which has a high failure rate compared to long-acting and reversible contraceptive methods. The low uptake of long-acting and reversible contraceptive methods may be due to barriers such as lack of availability, fear, misconceptions, and provider bias on the provision of long-acting methods for adolescents $(37,38)$.

Trends of injection methods of contraception rose from $1.6 \%$ to $29.1 \%$, while the patterns observed in condoms and pill declined from $1.1 \%$ to $0.1 \%$ and $3.2 \%$ to $1.8 \%$ respectively between 2000 and 2016 . This finding indicated that adolescent girls appear to be shifting away from condoms and pills, and choosing injectable contraceptives. This finding is comparable with a study from Kenya and Rwanda, where, injectable contraceptives have been consistently dominant among women aged 15-24 years (39). A possible reason could be due to their fertility intention. Adolescent girl intends to delay or space births for a short period which might explain their preference for short-acting methods that are easier to start and stop as needed (40).

Although there are visible changes in the trend of contraceptive use and knowledge of contraception was almost universal, still more than three-fifths of sexually active female adolescents are not using the contraception according to 2016 EDHS. This finding was slightly lower than the report from LMICs where 
$42-68 \%$ of sexually active adolescent females in all the Latin American countries (except Guatemala and Haiti) and in Bangladesh, Indonesia, Kazakhstan, and Turkey were currently using contraceptives (40). However, it is higher than the results from the African countries where contraceptive prevalence was 20$35 \%$, except in Namibia in which it reached at least $40 \%$ (40). This finding was also slightly higher than Zimbabwe and Malawi's study, where $35 \%$ and $33 \%$ of adolescents use a contraceptive, respectively (39). Hence, ensuring access and choice of family planning to improve maternal and neonatal health is crucial.

There were significant variations in the use of contraception by background characteristics of adolescent girls in Ethiopia. This study revealed that respondent's education was an independent predictor for contraceptive use. This was similar to a study conducted in Nigeria and Burkina Faso where contraceptive use among adolescents who attended secondary/above education was higher than those who had completed primary education (28). Similarly, in Ghana, the odds of contraceptive use were higher among educated female adolescents (41). Further, low contraceptive use among illiterate female adolescents was reported in Bangladesh (42). This may be because educated girls are more likely to appreciate the dividend that contraceptive use has on their lives. Also, they may have a plan to pursue the highest career within their education as a result; they want to delay their childbearing time.

The likelihood of contraceptive use increased significantly with the increase in household economic status. This finding was in line with a report from three African countries: Nigeria, Burkina Faso, and Ethiopia. Across all these countries, there is a significant equity gap in modern contraception use because of the wealth status (28). Likewise, another study in Ethiopia showed that women from richer households were more likely to use contraception (27). This could be because, most of the small resources obtained from the petty jobs done by women, and their spouses in poor households are diverted for taking care of the family and less is shifted to the health of the mothers. Hence, women from poor households refused the service as they encountered difficulties to cover direct and indirect costs incurred in seeking the services (43).

Further, adolescents who had been told about FP during a health facility visit used contraception more than those who were not told about FP. The existing literature indicated that female adolescent's access to family planning information via different sources increases the use of modern contraceptive methods. For instance, in Nigeria hearing about family planning on mass media was associated with the use of modern contraceptives (44). Also, being visited by a community health worker resulted in an inclination for modern contraceptive methods (45). Access to information plays a significant role in the use of contraception as it can raise an individual's awareness, and influence their attitude, and could guide them to make an informed decision to use the services. However, in the present study, only $15 \%$ of those who visit health facilities are told about contraception that indicated many sexually active adolescent girls miss out on this information.

A systematic review conducted in 2011 and updated in 2016, on youth-friendly family planning services for young people indicated the importance that young people place on receiving comprehensive, clientcentered family planning counseling (35). However, several factors were identified as barriers to the 
delivery of effective contraceptive counseling and care for adolescents. For instance, in Latin America, many consider adolescent use of contraception to be socially unacceptable (46). As there were significant associations between FP counseling with contraceptive initiation and continuation, health care provider skills in the counseling, and provision of contraception for an adolescent is, therefore, needed to be emphasized (47).

The main strength of this study was the use of nationally representative data. The study has also some limitations, the small sample sizes that contributed to a bit wider confidence level for some variables. Possibility of social desirability bias that may result in under-reporting of sexual activity. The information was self-reported and it may not indicate the true picture of contraceptive practice by an adolescent. The data are from a cross-sectional survey and unable to establish any causal relationship between a response variable (contraceptive use) and the covariates of interest.

\section{Conclusion And Recommendation}

A considerable proportion of female adolescents are experiencing an early marriage. There is an increment in the trend of contraceptive use among sexually active female adolescents in Ethiopia between 2000 to 2016. There is a change in the pattern of long-acting and reversible contraceptive methods. Personal, socioeconomic (macro), and health care system (intermediate) factors determine the contraceptive practices among sexually adolescent girls in Ethiopia

Governments must develop more targeted strategies for improving adolescent's socioeconomic and education status. This will not only increase contraceptive prevalence, but will also reduce teenage pregnancy and birth, and in turn, contribute to the achievement of the Sustainable Development Goal 3 of good health and well-being. Improving contraception use among sexually active adolescents will also require connecting adolescents with information and services during their routine health service visits and taking advantage of missed opportunities for contact with the health facility.

Strengthening school and community-based programs to address the school environment and/or community attitudes toward early marriage are important. Also, the consequence of early marriage should be emphasized on the integrated life skill and comprehensive sexuality education. Legal issues around early marriage- enforcing laws on age at marriage should be strengthened.

\section{List Of Abbreviations}

AOR: Adjusted odd Ratio, COR: Crude odd Ratio, DHS: Demographic and Health Surveys, EAs: Enumeration areas, EDHS: Ethiopian Demographic and Health Surveys, HIV/AIDS: Human immunodeficiency virus infection and acquired immune deficiency syndrome, IUCD: Intra-Uterine Contraceptive Device, SPSS: Statistical Package for the Social Sciences, STIs: Sexual transmitted infections, TV: Television 


\section{Declarations}

Ethics approval and consent to participate: Manuscript has adhered to the ethical standards. The data set was requested from the Measure DHS program. Approval was then granted to download the data.

Consent for publication: Not applicable

Availability of data and materials: The datasets used and/or analyzed during the current study are available from the corresponding author on reasonable request

Competing interests: The authors do not have any conflicting interests to declare.

Funding: There was no funding for this work.

Authors' contributions: AK, SB, AK, YB, Protocol development, AK and SB data analysis and Manuscript preparation, and all authors read and approved the final manuscript.

\section{Acknowledgment}

We would like to thank the Demographic and Health Surveys (DHS) Program for availing of the data. We also thank professor Susan Anand and Dr. Daniel Taye Feyisa for their support in proofreading this paper.

Availability of data and materials: The raw data available at https://dhsprogram.com/publications/publication-fr328-dhs-final-reports.cfm

\section{References}

1. Institute of Medicine 2005. Growing Up Global: The Changing Transitions to Adulthood in Developing Countries. Washington DTNAP https://doi. org/10. 17226/1117. The national academies press.

2. Chandra-Mouli V, Parameshwar PS, Parry M, Lane C, Hainsworth G, Wong S, et al. A never-before opportunity to strengthen investment and action on adolescent contraception , and what we must do to make full use of it. 2017;1-13.

3. Patton et al. Lancet (2016). Our future: a Lancet commission on adolescent health and wellbeing 387(10036): 2423-2478. Doi: 10.1016/S0140-6736(16)00579-1.

4. UNICEF. Adolescent Demographics UNICEF Data. 2016. Available at https://data.unicef.org/topic/adolescents/overview/: 2016;2016.

5. Engelman R, Rosen JE, Wong, Sylvia.The power of 1.8 billion. Adolescents, youth and the transformation of the future.UNFPA. 2014 state of world population. 1.8 billion. 2014;

6. Report AC. World Population Monitoring. Adolescents and Youth, A Concise Report United Nations, New York, 2012

7. Nations U. Transforming our world: the 2030 agenda for sustainable development.2015. Available from: https://sustainabledevelopment.un.org/content/documents/21252030 Agenda for 
Sustainable Development web.pdf

8. The global Strategy For women's,Children's and Adolescents' Health Every women every child (20162030) 2016.

9. Sheehan P, Sweeny K, Rasmussen B, Wils A, Friedman HS, Mahon J, et al. Health Policy Building the foundations for sustainable development: a case for global investment in the capabilities of adolescents. Lancet. 2017;6736(17).

10. Darroch JE, Woog V, Bankole A, Ashford LS. ADDING IT UP: Costs and Benefits of Meeting the Contraceptive Needs of Adolescents. 2018;(May 2016).

11. Starrs AM, Ezeh AC, Barker G, Basu A, Bertrand JT, Blum R, et al. The Lancet Commissions Accelerate progress - sexual and reproductive health and rights for all: report of the Guttmacher - Lancet Commission. 2018;391.

12. Iqbal Shah \& Elisabeth Åhman (2004) Age Patterns of Unsafe Abortion in Developing Country Regions, Reproductive Health Matters, 12:sup24, 9-17, DOI: 10.1016/ S0968-8080(04)24002-2.

13. WHO (2011). Guidelines for preventing early pregnancy and poor reproductive outcomes among adolescents in developing countries

14. Ganchimeg T, Ota E, Morisaki N, Laopaiboon M, Lumbiganon P, Zhang J, Yamdamsuren B, Temmerman M, Say L, Tunc ?alp € O, Vogel JP, Souza JP, Mori R, on behalf of the WHO Multicountry Survey on Maternal Newborn Health Research Network. Pregnancy and childbirth. outcomes among adolescent mothers: a World Health Organization multicounty study. BJOG 2014; 121 (Suppl. 1): 4048.

15. Gibbs CM, Wendt A, Peters S, Hogue CJ. The Impact of Early Age at First Childbirth on Maternal and Infant Health. 2012;26:259-84.

16. The World Bank. 2007. World development report. Development and the Next Generation.

17. Elisabeth L. Åhman \& Iqbal H. Shah (2010) Contraceptive use, fertility, and unsafe abortion in developing countries, The European Journal of Contraception \& Reproductive Health Care, 15:sup2, S77-S82, DOI: 10.3109/13625187.2010.533004.

18. Biddlecom A, Riley T, Darroch JE, Sully E, Kantorová V. Future Scenarios of Adolescent Contraceptive Use, Cost and Impact in Developing Regions. 2018;(August).

19. John Cleland, Mohamed M Ali \& Iqbal Shah (2006) Trends in Protective Behaviour among Single vs. Married Young Women in Sub-Saharan Africa: The Big Picture, Reproductive Health Matters, 14:28, 17-22, DOI: 10.1016/S0968-8080(06)28250-8.

20. Sedekia Y, Jones C, Nathan R, Schellenberg J, Marchant T. Using contraceptives to delay first birth : a qualitative study of individual, community and health provider perceptions in southern Tanzania. 2017;1-13.

21. United Nations Population Fund (UNFPA) and ICPD25. Sexual and Reproductive Health and Rights: An essential element of Universal Health Coverage. Integrated definition of sexual and reproductive health and rights. https://www.unfpa.org/sites/default/files/pubpdf/UF_SupplementAndUniversalAccess_30 online.pdf 
22. Fact sheet on teenage pregnancy in Ethiopia. Retraved in August 2020 https://www.rutgers.international/sites/rutgersorg/files/PDF/RHRNHLPF_A4leaflet_Ethiopia.pdf.

23. Federal democratic Republic of Ethiopia .Ministry of health . National Reproductive Health strategy (2016-2020), 2016.

24. Federal democratic Republic of Ethiopia .Ministry of health . National Reproductive health Strategy 2006 - 2015 ,(March 2006).

25. Federal democratic Republic of Ethiopia . Ministry of youth,sport and culture. Ethiopian national youth policy. March 2004.

26. Federal democratic Republic of Ethiopia .Ministry of health . National adolescent and Youth Health strategy (2016-2020),2016.

27. Fekadu GA, Omigbodun AO, Roberts OA, Yalew AW. Factors associated with long acting and permanent contraceptive methods use in Ethiopia. 2019;3:1-11

28. Hounton S, Barros AJD, Amouzou A, Shiferaw S, Mai A, Akinyemi A. Patterns and trends of contraceptive use among sexually active adolescents in Burkina Faso, Ethiopia, and Nigeria: evidence from cross-sectional studies. 2015;1(October):1-11

29. WHO (2012) .Sixty-Fifth World Health Assembly. Early marriages, adolescent and young pregnancies, Report by the Secretariat. 16 March 2012.

30. Montazeri S, Gharacheh M, Mohammadi N, Rad JA, Ardabili HE. Determinants of Early Marriage from Married Girls ' Perspectives in Iranian Setting: A Qualitative Study. 2016;2016.

31. Nicola J. e tal. September 2014. Early marriage and education: the complex role of social norms in shaping Ethiopian adolescent girls'lives. Country Report.

32. Raj A, Salazar M, Jackson EC, Wyss N, Mcclendon KA, Khanna A. Students and brides: a qualitative analysis of the relationship between girls ' education and early marriage in Ethiopia and India. 2019;1-20.

33. Erulkar A. Adolescence lost: The realities of child marriage. J Adolesc Heal [Internet]. 2013;52(5):513-4. Available from: http://dx.doi.org/10.1016/j.jadohealth.2013.03.004

34. Erica Sedlander, Jeffrey B. Bingenheimer, Mark C. Edberg, Rajiv N. Rimal, Hina Shaikh and Wolfgang Munar. Understanding modern contraception uptake in one Ethiopian community: a case study. Reproductive Health (2018) 15:111 https://doi.org/10.1186/s12978-018-0550-3

35. Brittain et al. Youth-Friendly Family Planning Services for Young People: A Systematic Review Update. Am J Prev Med. 2018 November; 55(5): 725-735. doi: 10.1016/j.amepre.2018.06.010. surveys. Lancet Glob Health 2019; 7: e904-11 http://dx.doi.org/10.1016/.

36. USAID, Pathfinder International and John Snow, Inc. Scaling Up Community-Based Service Delivery of Implanon: The Integrated Family Health Program's Experience Training Health Extension Workers, January 2010. http://www2.pathfinder.org/site/DocServer/LAFP.pdf?docID=18321.

37. Susan Ontiri, Gathari Ndirangu, Mark Kabue, Regien Biesma, Jelle Stekelenburg and Collins Ouma. Long-Acting Reversible Contraception Uptake and Associated Factors among Women of 
Reproductive Age in Rural Kenya. 2019. Int. J. Environ. Res. Public Health 2019, 16, 1543; doi:10.3390/ijerph16091543

38. C.Emily Hendrick, Joshua N. Cone, Jessica Cirullo, Julie Maslowsky. Determinants of Long-Acting Reversible Contraception (LARC) Initial and Continued Use Among Adolescents in the United States. 2019 Adolescent Research Review https://doi.org/10.1007/s40894-019-00126-w

39. Dennis ML, Radovich E, Wong KLM, Owolabi O, Cavallaro FL, Mbizvo MT, et al. Pathways to increased coverage: An analysis of time trends in contraceptive need and use among adolescents and young women in Kenya, Rwanda, Tanzania, and Uganda. Reprod Health. 2017;14(1):1-13.

40. Tsui AO, Trevitt JL, Blanc AK, Gates M. Patterns and Trends in Adolescents ' Contraceptive Use and Discontinuation in Developing Countries and Comparisons. 2009;35(2):63-71.

41. Nyarko SH. Prevalence and correlates of contraceptive use among female adolescents in Ghana. Women's Health (2015) 15:60 ; DOI 10.1186/s12905-015-0221-2

42. Hossain ME, Hoq MN. Determinants of Contraception Use among Female Adolescents in Bangladesh Determinants of Contraception Use among Female Adolescents in Bangladesh. 2012;(September).

43. Nakirijja DS. iMedPub Journals Socio-economic Determinants of Access to and Utilization of Contraception among Rural Women in Uganda: The Case of Wakiso District Background of the Research. 2018;1-20

44. Chima V, Alawode OA, Peter S, Kibira S. contraceptive use among female adolescents in rural Nigeria: Does exposure to family planning messages matter? A cross-sectional study [ version 2; peer review: 1 approved ] Gates Open Research This article is included in the International. 2019;113

45. Mohamad I. Brooks1, Nicole E. Johns, Anne K. Quin, Sabrina C. Boyce, Ibrahima A. Fatouma, Alhassane O. Oumarou, Aliou Sani and Jay G. Silverman. Can community health workers increase modern contraceptive use among young married women? A cross-sectional study in rural Niger. Reproductive Health (2019) 16:38. https://doi.org/10.1186/s12978-019-0701-1

46. Bitzer J, Abalos V, Apter D, Martin R, Black A; Global CARE (Contraception: Access, Resources, Education) Group. Targeting factors for change: contraceptive counselling and care of female adolescents. Eur J Contracept Reprod Health Care. 2016, 21(6):417-430. doi:

10.1080/13625187.2016.1237629. Epub 2016

47. Pradesh U, Dehingia N, Dixit A, Averbach S, Choudhry V, Dey A, et al. Family planning counseling and its associations with modern contraceptive use, initiation, and continuation in rural. 2019;1-11.

\section{Tables}

Table 1 : Distribution of sexually active female adolescents age $15-19$ by their background characteristics, Ethiopia DHS 2016 


\begin{tabular}{|c|c|c|c|}
\hline \multicolumn{2}{|l|}{ Variable } & \multirow{2}{*}{$\begin{array}{l}\text { Frequency } \\
161\end{array}$} & \multirow{2}{*}{$\begin{array}{l}\text { Percent } \\
32.0\end{array}$} \\
\hline Age category & $15-17$ & & \\
\hline \multicolumn{2}{|c|}{$18-19$} & 343 & 68.0 \\
\hline \multirow[t]{3}{*}{ Education of respondent } & No education & 143 & 28.4 \\
\hline & Primary & 305 & 60.6 \\
\hline & Secondary and above & 56 & 11.0 \\
\hline \multirow[t]{2}{*}{ Place of residence } & Urban & 64 & 12.7 \\
\hline & Rural & 440 & 87.3 \\
\hline \multirow[t]{3}{*}{ Marital status } & Married & 458 & 91.0 \\
\hline & Never married & 23 & 4.5 \\
\hline & Divorced/separated & 23 & 4.5 \\
\hline \multirow[t]{3}{*}{ Wealth index } & Poor & 230 & 45.6 \\
\hline & Average & 97 & 19.3 \\
\hline & Rich & 177 & 35.1 \\
\hline \multirow[t]{4}{*}{ Religion } & Muslim & 211 & 41.9 \\
\hline & Orthodox Christian & 201 & 39.9 \\
\hline & Other Christian & 90 & 17.9 \\
\hline & Other & 2 & 0.3 \\
\hline \multirow[t]{9}{*}{ Ethnicity } & Oromo & 199 & 39.5 \\
\hline & Amhara & 155 & 30.7 \\
\hline & Tigraie & 34 & 6.8 \\
\hline & Sidama & 22 & 4.4 \\
\hline & Somalie & 17 & 3.3 \\
\hline & Walaita & 12 & 2.4 \\
\hline & Gamo & 10 & 1.9 \\
\hline & Guragie & 8 & 1.5 \\
\hline & Other & 48 & 9.4 \\
\hline \multirow[t]{2}{*}{ Respondent occupation } & Not working & 300 & 59.6 \\
\hline & Agriculture & 102 & 20.3 \\
\hline
\end{tabular}




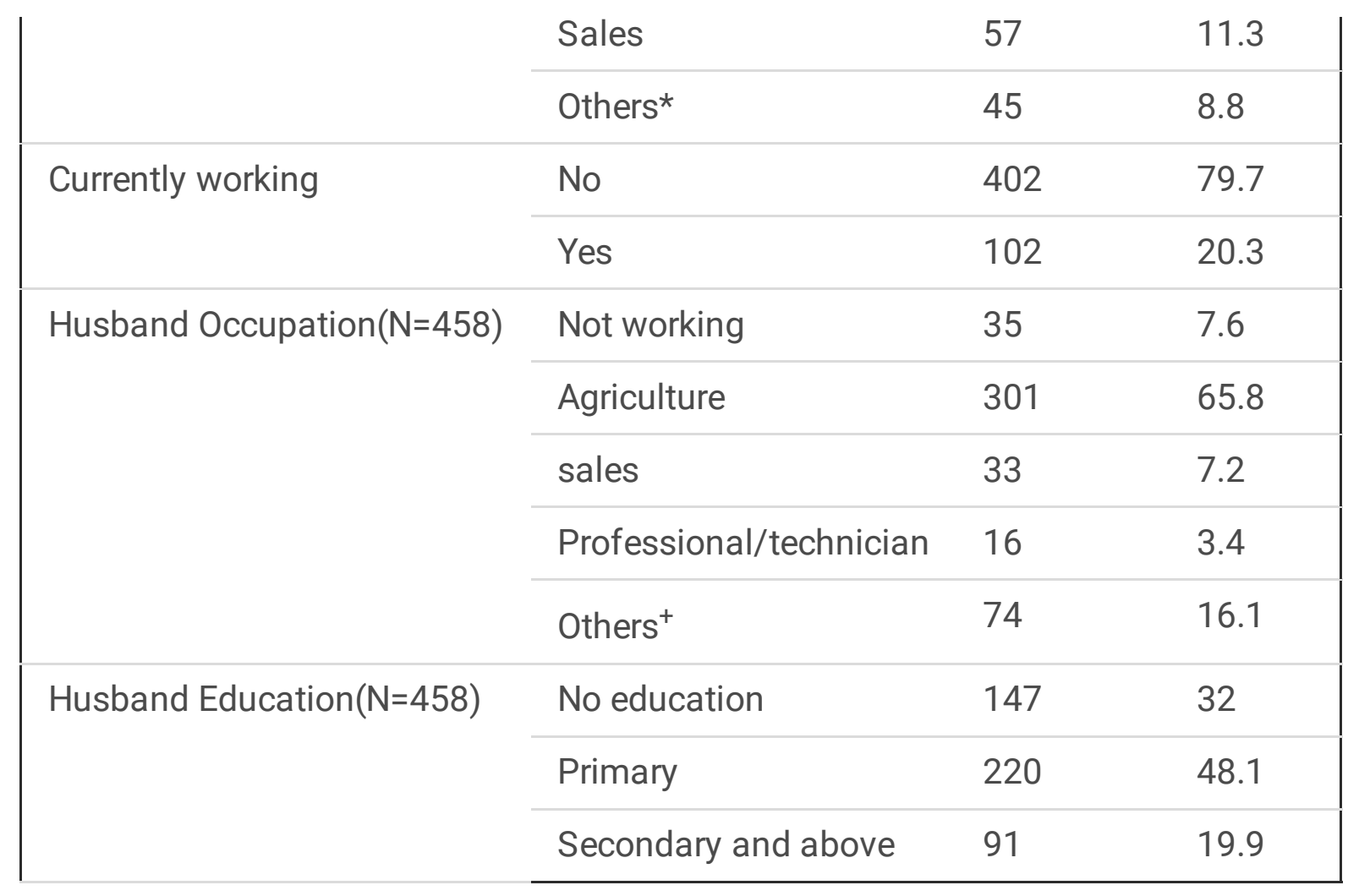

*professional/managerial/technical, services, skilled and unskilled manual

${ }^{+}$skilled and unskilled manual, services, I don't know

Table 2: Distribution of adolescents age 15-19 by their exposure to family planning information, knowledge about fertility and contraceptive method, Ethiopia DHS 2016 


\begin{tabular}{|c|c|c|c|}
\hline Variables & & Frequency & Percent \\
\hline \multirow{2}{*}{$\begin{array}{l}\text { Heard family planning message on radio on last few } \\
\text { months }\end{array}$} & Yes & 91 & 18.1 \\
\hline & No & 413 & 81.9 \\
\hline \multirow{2}{*}{$\begin{array}{l}\text { Watch family planning messages on TV on last few } \\
\text { months }\end{array}$} & Yes & 68 & 13.4 \\
\hline & No & 436 & 86.6 \\
\hline \multirow{2}{*}{$\begin{array}{l}\text { Read about family planning messages on } \\
\text { newspaper/magazine last few months }\end{array}$} & Yes & 21 & 4.2 \\
\hline & No & 483 & 95.8 \\
\hline \multirow{2}{*}{$\begin{array}{l}\text { Received family planning text message on mobile } \\
\text { phone }\end{array}$} & Yes & 5 & 1.1 \\
\hline & No & 498 & 98.9 \\
\hline \multirow{2}{*}{$\begin{array}{l}\text { Visited by field worker in the last } 12 \\
\text { months }\end{array}$} & Yes & 101 & 20.1 \\
\hline & No & 402 & 79.9 \\
\hline \multirow{2}{*}{$\begin{array}{l}\text { Field worker talk about family } \\
\text { planning }\end{array}$} & Yes & 50 & 9.9 \\
\hline & No & 51 & 10.2 \\
\hline \multirow{2}{*}{$\begin{array}{l}\text { Visited health facility in the last } 12 \\
\text { months }\end{array}$} & Yes & 211 & 42.0 \\
\hline & No & 292 & 58.0 \\
\hline \multirow{2}{*}{$\begin{array}{l}\text { Told about family planning in the health } \\
\text { facility }\end{array}$} & Yes & 77 & 15.3 \\
\hline & No & 135 & 26.7 \\
\hline \multirow[t]{6}{*}{ Knowledge of ovulatory period } & $\begin{array}{l}\text { During her } \\
\text { period }\end{array}$ & 37 & 7.3 \\
\hline & $\begin{array}{l}\text { After period } \\
\text { ended }\end{array}$ & 148 & 29.4 \\
\hline & $\begin{array}{l}\text { Middle of the } \\
\text { cycle }\end{array}$ & 76 & 15.0 \\
\hline & $\begin{array}{l}\text { Before period } \\
\text { begins }\end{array}$ & 33 & 6.5 \\
\hline & At any time & 116 & 23.0 \\
\hline & Do not know & 95 & 18.8 \\
\hline \multirow[t]{3}{*}{ Knowledge about any contraceptive method } & $\begin{array}{l}\text { Knows no } \\
\text { method }\end{array}$ & 7 & 1.3 \\
\hline & $\begin{array}{l}\text { Knows only } \\
\text { traditional } \\
\text { method }\end{array}$ & 4 & 0.7 \\
\hline & Knows modern & 494 & 98.0 \\
\hline
\end{tabular}




\begin{tabular}{|c|c|c|c|}
\hline & method & & \\
\hline \multirow[t]{3}{*}{ Number of living children } & No child & 308 & 61.1 \\
\hline & One child & 173 & 34.4 \\
\hline & Two and more & 22 & 4.5 \\
\hline \multirow[t]{3}{*}{ Decision maker on contraceptive use } & $\begin{array}{l}\text { Mainly } \\
\text { Respondent }\end{array}$ & 34 & 19.7 \\
\hline & Mainly husband & 3 & 1.9 \\
\hline & Joint decision & 133 & 78.4 \\
\hline
\end{tabular}

Table 3: Bivariate and multivariate logistic regression model showing predictors of contraceptive use among sexually active adolescents, 2016 EDHS 


\begin{tabular}{|c|c|c|c|}
\hline Variables and its category & & $\operatorname{COR}[95 \% \mathrm{Cl}]$ & AOR [95\% Cl] \\
\hline \multirow[t]{2}{*}{ Adolescent age category } & $15-17$ & $\begin{array}{l}.408 \quad(.270 \\
.616)\end{array}$ & $\begin{array}{l}.524 \\
1.260)\end{array}(.218$ \\
\hline & $18-19$ & 1 & 1 \\
\hline \multirow[t]{2}{*}{ Place of residence } & Urban & $\begin{array}{l}3.256(1.882 \\
5.632)\end{array}$ & $\begin{array}{l}0.692(.113 \\
4.238)\end{array}$ \\
\hline & Rural & 1 & 1 \\
\hline \multirow[t]{2}{*}{$\begin{array}{l}\text { Heard family planning on radio } \\
\text { last few months }\end{array}$} & Yes & $\begin{array}{l}2.365(1.491 \\
3.750)\end{array}$ & $\begin{array}{l}1.046 \\
2.699)\end{array}(.405$ \\
\hline & No & 1 & 1 \\
\hline \multirow[t]{2}{*}{$\begin{array}{l}\text { Heard family planning on TV last } \\
\text { few months }\end{array}$} & Yes & $\begin{array}{l}3.323(1.943 \\
5.682)\end{array}$ & $\begin{array}{l}0.374 \\
1.506)\end{array}(.093$ \\
\hline & No & 1 & 1 \\
\hline \multirow[t]{2}{*}{ Told about FP at health facility } & Yes & $\begin{array}{l}3.083 \\
5.523)\end{array}(1.721$ & $\begin{array}{l}3.115 \\
7.007) *\end{array}$ \\
\hline & No & 1 & 1 \\
\hline \multirow[t]{3}{*}{ Husband Education } & No education & $\begin{array}{l}.422 \\
.722)\end{array}$ & $\begin{array}{l}1.083 \\
3.671)\end{array}(.320$ \\
\hline & Primary & $\begin{array}{l}.445 \\
.731)\end{array} \quad(.271$ & $\left.\begin{array}{l}0.330 \\
1.015)\end{array}\right)(.107$ \\
\hline & Secondary \& above & 1 & 1 \\
\hline \multirow[t]{3}{*}{ Wealth Index } & Poor & 1 & 1 \\
\hline & Average & $\begin{array}{l}1.886(1.135 \\
3.134)\end{array}$ & $\begin{array}{l}0.424 \\
1.380)\end{array}(.130$ \\
\hline & Rich & $\begin{array}{l}4.701(3.070, \\
7.198)\end{array}$ & $\begin{array}{l}3.662 \\
9.913) *\end{array}$ \\
\hline \multirow[t]{4}{*}{ Respondent occupation } & Not working & 1 & 1 \\
\hline & Agriculture & $\begin{array}{l}1.407 \\
2.222)\end{array}(.891$ & $\begin{array}{l}1.841 \\
5.359)\end{array}(.632$ \\
\hline & Sales & $\begin{array}{l}2.730 \\
5.154)\end{array}(1.447$ & $\begin{array}{l}2.599 \\
17.455)\end{array}$ \\
\hline & $\begin{array}{l}\text { Others (skilled, unskilled } \\
\text { manual) }\end{array}$ & $\begin{array}{l}1.048 \\
1.902)\end{array}(.577$ & $\begin{array}{l}0.468 \\
2.587)\end{array}(.085$ \\
\hline \multirow[t]{2}{*}{ Respondent education } & No education & $\begin{array}{ll}.206 & (.106 \\
.399)\end{array}$ & $\begin{array}{l}0.044 \\
.231)^{*}\end{array} \quad(.008$ \\
\hline & Primary & $.369 \quad(.203$ & $0.101 \quad(.024$ \\
\hline
\end{tabular}


Secondary \& above

Currently working
Yes

No
1

$1.797(1.160$

2.784)

$2.622(.660$

10.412)

* Significant value at 0.05

\section{Figures}

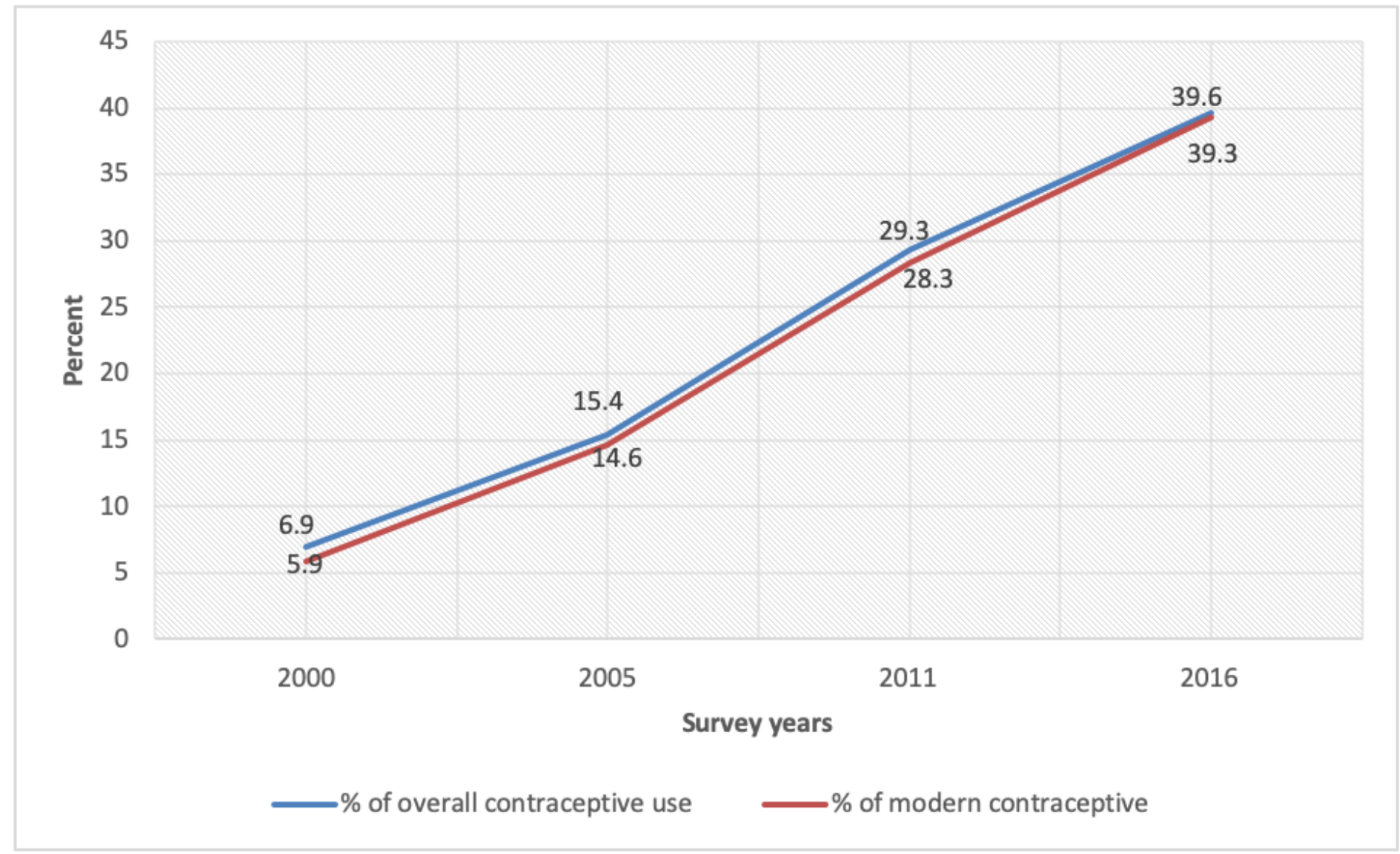

\section{Figure 1}

Trends in use of modern contraceptives among sexually active adolescent, Ethiopia DHS 2000-2016 


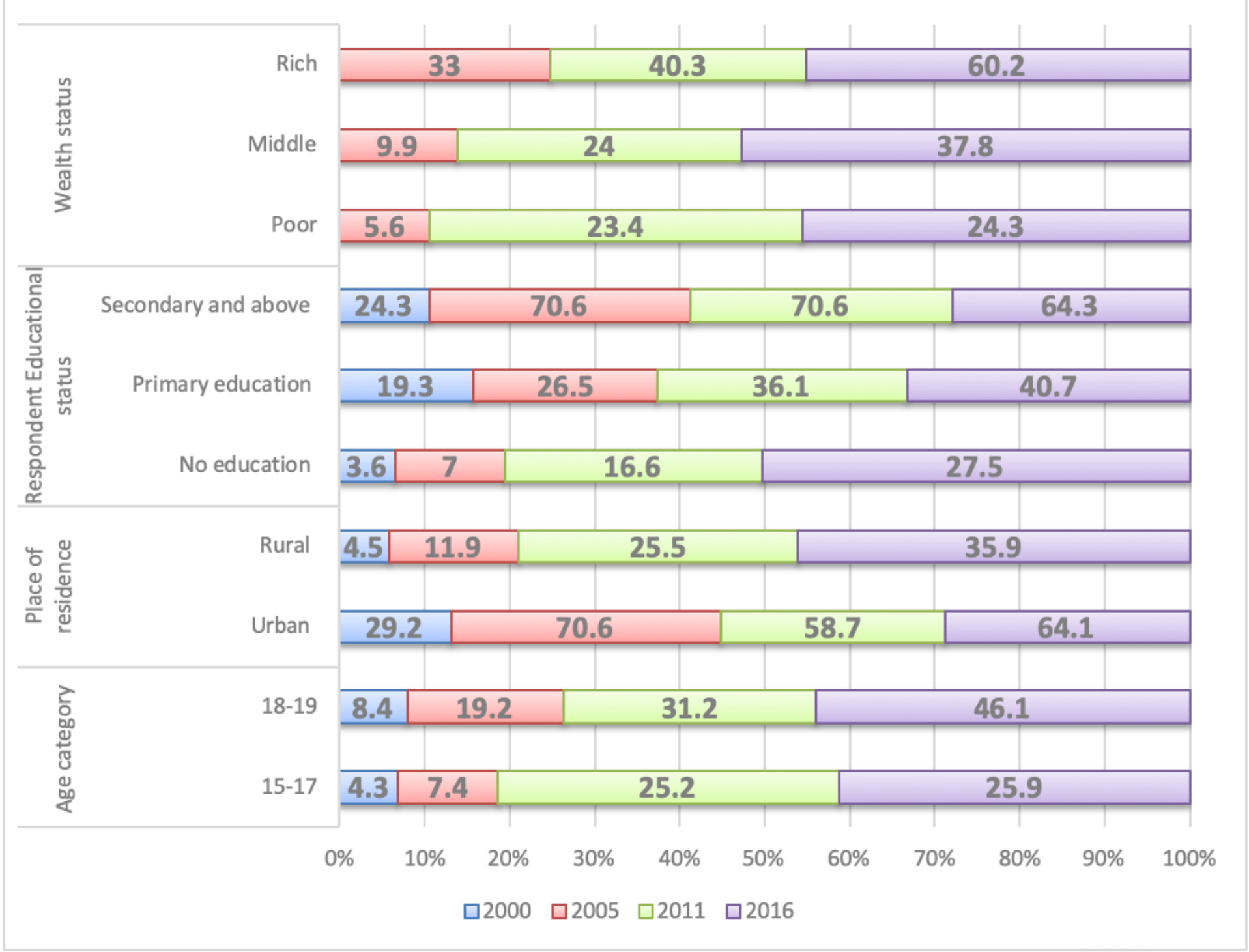

\section{Figure 2}

Differentials in contraceptive use among sexually active adolescent by background characteristics, Ethiopia DHS 2000-2016 


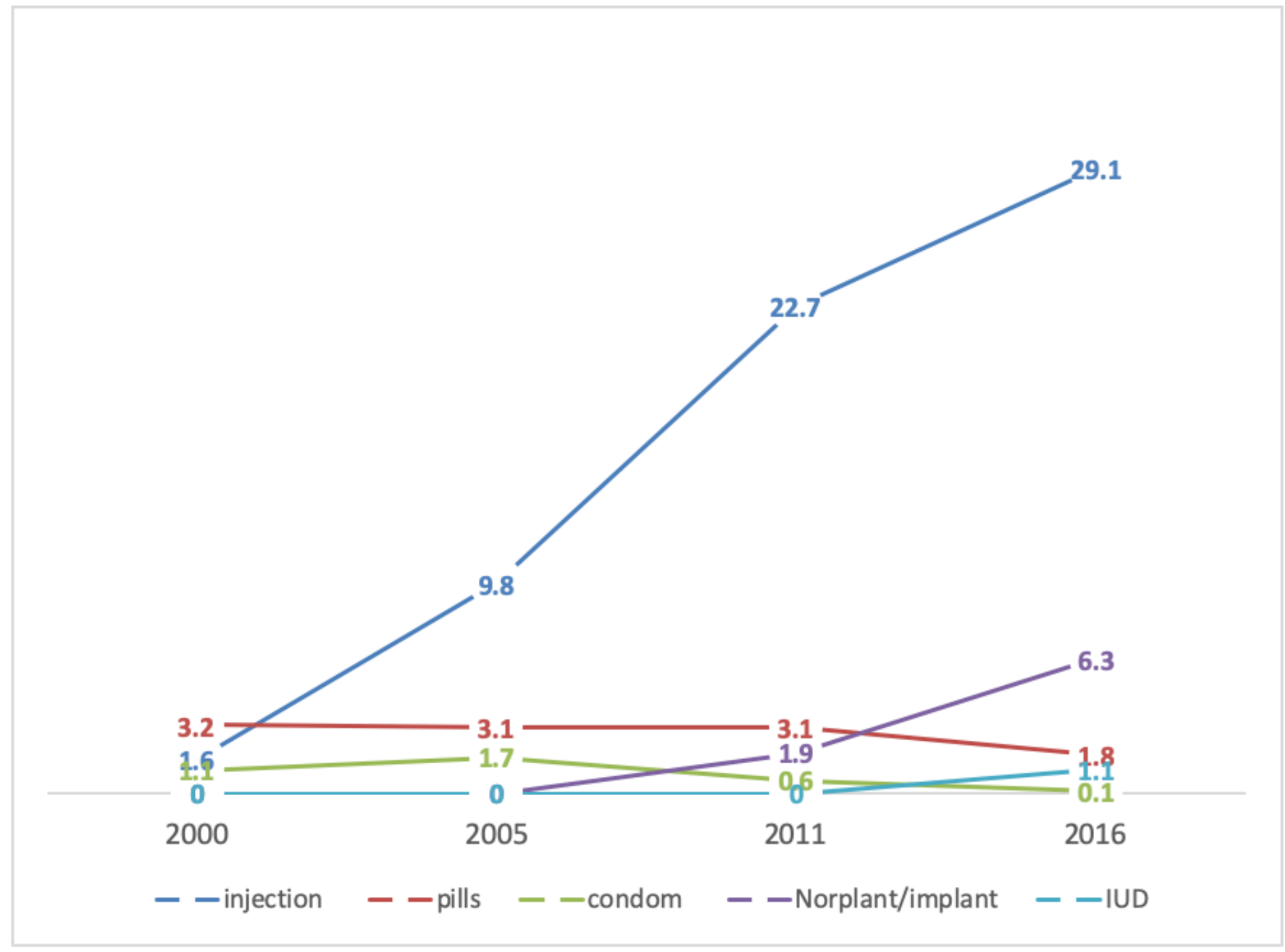

\section{Figure 3}

Trends in method mix contraceptive use among sexually active adolescent, Ethiopia DHS 2000-2016

\section{Supplementary Files}

This is a list of supplementary files associated with this preprint. Click to download.

- supplementaryfile.docx 